\title{
Influence of alcohol intake during lactation in the origin of alcohol addiction
}

\author{
Influência da ingesta de álcool durante a lactação na origem do alcoolismo
}

Patrícia Bossolani Charlo Sanches ${ }^{1}$, Victor Augusto Pacheco ${ }^{1}$, Amanda Platkitka Maximiano ${ }^{1}$, Marcelo Picinin Bernuci $^{1}$

Objective: to analyze the influence of alcohol intake during lactation in alcoholism onset. Methods: descriptive research with intentional convenient sample of 33 people addicted to alcohol and their mothers which assessed the correlation between the consumption of alcohol ingested using the instruments Cut down, Annoyde by criticims, Guilty and Eye-opener, and Tolerance, Annoyed, Cut down and Eye-opener. Results: addicts are men, young, single, with low level of education and income between one and five minimum wages. Among the patients who consider themselves alcoholics, 55.5\% had mothers who considered themselves alcoholics and $60.0 \%$ of them had consumed alcohol during lactation, but this correlation was not significant. Conclusion: a positive correlation between alcohol consumption by mothers during breastfeeding and addiction of their children in adulthood was not found.

Descriptors: Alcoholism; Woman's Health; Public Health.

Objetivo: analisar a influência da ingestão de álcool durante a lactação na origem do alcoolismo. Métodos: pesquisa de caráter descritivo, com amostra intencional por conveniência com 33 dependentes alcoólicos e suas respectivas mães, avaliando a correlação do consumo de álcool ingerido utilizando os instrumentos Cut down, Annoyde by criticims, Guilty e Eye-opener, e Tolerance, Annoyed, Cut down e Eye-opener. Resultados: os dependentes são homens, jovens, solteiros, com baixo grau de escolaridade e renda entre um e cinco salários mínimos. Dos pacientes que se consideram alcoólatras, 55,5\% possuíam mães que se consideraram alcoólatras e 60,0\% delas consumiram álcool durante a lactação, mas esta correlação não foi significativa. Conclusão: não se constatou correlação positiva entre o consumo de álcool pelas mães durante a amamentação com o vício de seus filhos na fase adulta.

Descritores: Alcoolismo; Saúde da Mulher; Saúde Pública.

${ }^{1}$ Centro Universitário de Maringá. Maringá, PR, Brazil. 


\section{Introduction}

Alcohol is the most frequently consumed drug in the world by both men and women and its continued use and abuse can lead to addiction, and this may be associated with environmental, social and genetic factors $^{(1)}$. A fact that has received attention is the high incidence of alcohol consumption among women, especially in economically emerging countries, in which women have gained financial independence ${ }^{(2)}$.

In Brazil, despite some educational campaigns alerting the female population, a considerable part of this population is still observed consuming alcohol. There are reports that $5.0 \%$ of the female population constantly drinks alcohol, and about $10.0 \%$ of these women still continue the consumption during pregnancy and lactation ${ }^{(3)}$.

Although negative effects of alcohol consumption during pregnancy on fetal development have been extensively investigated, specially showing that this event is associated with an increased risk of defects in the fetus ${ }^{(4)}$, few studies have evaluated the effects of alcohol ingested by mothers during the nursing process upon the development of the infant. In general, alcohol intake during lactation impairs the process of production and secretion of breast milk and induce changes in the composition and odor of milk that promote significant reduction in milk consumption by the infant. In this case, dietary restriction adversely interferes in the subsequent development of the infant, resulting in psychomotor alterations and low immunity ${ }^{(5)}$.

As alcohol levels found in milk are close to those of maternal blood, which reaches its peak about 3060 minutes after ingestion ${ }^{(5)}$, it is possible to suggest that some of the negative effects of alcohol during the lactation process over the development of the infant can be directly related to the transmission of alcohol metabolites from the mother to child through the milk. Coupled with the fact that early alcohol use (before age of 14) is associated with increased risk of alcohol abuse in adulthood, it is possible to propose a possible relationship between early exposure to alcohol, such as during pregnancy and lactation, and the onset of alcohol dependence in adults ${ }^{(5)}$.

However, there is no evidence so far showing that alcohol intake during lactation can induce addiction to alcohol in adults. Thus, we propose in this study to describe the habits of alcoholic mothers during the breastfeeding process and the habits of the children during adulthood and associate these factors in an attempt to elucidate a possible explanation for the origin of addiction. We believe that information and explanations on the effect of adverse events during childhood over the behavioral development in the adult individual can be of great value to the development of public policies aimed at maternal and child health. In particular, with regard to alcohol intake by pregnant and/or breastfeeding women, such investigation may guide subsequent studies related to the origin of addiction to drugs in their children.

Thus, this study aimed to analyze the influence of alcohol intake during lactation over the origin of alcoholism.

\section{Methods}

This study is characterized as descriptive, with intentional and convenient sample. Data collection of this research was conducted in the Psychosocial Care Center Alcohol and Drugs and Alcoholics Anonymous of the municipality of Maringá, Paraná, Brazil, during the period from July to October of 2015. The participants of this study were thirty-three $(n=33)$ individuals under treatment and their mothers. To perform the characterization of the socio-demographic profile of the alcoholics, a simple questionnaire was used, with objective questions to conduct a survey of the sociodemographic profile and to identify the individual's health condition. After collecting of data, they were statistically analyzed using descriptive statistics in the form of absolute and relative frequency.

In order to characterize and identify the main factors associated with the proximity of the 
alcoholics and their mothers with alcohol, a simple questionnaire was used. This had objective questions about the reason for the proximity with alcohol, the types of beverages consumed and the frequency of consumption, described and statistically analyzed through absolute and relative frequency. In order to implement the identification and correlation of alcohol use by mothers during the lactation process with the origin of the addiction in the child, the research was divided into two parts. For the development of this first part of the research with the alcoholics, we used the Cut down, Annoyde by criticims, Guilty and Eye-opener (CAGE) questionnaire, composed by four objective questions. Each question has a score corresponding to a point. The analysis is performed in the presence of at least two positive answers or a score greater than or equal to two, suggesting positive indication of alcohol dependence in outpatient treatment ${ }^{(6)}$. The second part of the interview was performed with alcoholic mothers through the instrument Tolerance, Annoyed, Cut down and Eye-opener (T-ACE), validated for Portuguese in $2001^{(7)}$. The Brazilian version was adapted with the aim to improve the acceptance by women, since the author noted some discomfort and resistance when presenting the questions to the pregnant women. This questionnaire also consists in four questions, with a total sum of points obtained from the answers which is no more than five, and from 0 to 2 points for the first question and from 0 to 1 point for the other. Thus, the case of mothers who had two or more affirmative responses suggests the intake of more than 28 daily grams of absolute alcohol ${ }^{(7)}$.

To analyze the data from these two instruments aiming to check the association of alcohol abuse by the mother with the child addiction in adulthood, the exact Fisher test was applied with the aid of the statistical environment R (R Development Core Team), in which a contingency table in $2 \times 2$ format was prepared, and from this, the probability of occurrence of the lowest observed value was estimated. The significance level was set at $\alpha=5 \%(p<0.05)$, so that a positive correlation would be indicated by $P$ values below the significance level ${ }^{(8)}$.

The study complied with the formal requirements set by national and international regulatory standards for research involving human beings.

\section{Results}

Table 1 was built with absolute frequency values; this table shows the profile of alcohol users. They were $100.0 \%$ male, $36.4 \%$ aged between 31 and 40 years and $66.7 \%$ were white. Regarding education, $33.3 \%$ attended elementary and high school, and only $12.1 \%$ had higher level. $69.7 \%$ had family income of about one to five minimum wages, and the same proportion of $69.7 \%$ were active in their professional activities. Regarding marital status, $60.7 \%$ were single or separated.

Table 1 - Sociodemographic characterization of alcohol-dependent

\begin{tabular}{lc}
\hline Variables & $\mathbf{f}(\%)$ \\
\hline Age & \\
$<20$ & $1(3.0)$ \\
$21-30$ & $6(18.2)$ \\
$31-40$ & $12(36.4)$ \\
$41-50$ & $9(27.3)$ \\
$51-60$ & $5(15.1)$ \\
Race & \\
White & $22(66.7)$ \\
Black & $5(15.1)$ \\
Mestizo/mulatto & $6(18.2)$ \\
Level of education & \\
Kindergarten & $7(21.2)$ \\
Primary school & $11(33.3)$ \\
High school & $11(33.3)$ \\
University & $4(12.1)$ \\
Monthly family income (minimum wage)* & \\
$>1$ & $10(30.3)$ \\
1 - 5 & $23(69.7)$ \\
employment activity & \\
Active & $23(69.7)$ \\
Inactive & $5(15.1)$ \\
Retired & $3(9.1)$ \\
Illnes aid & $2(6.0)$ \\
\hline Minimum wage: R $1,148.40$ & \\
\hline
\end{tabular}


Regarding the rates of alcohol consumption, the characterization of the relationship of the proximity between abuse with the degree of kinship of the alcoholics and their mothers, it was possible to identify and illustrate in Table 2 and the levels of consumption of the alcoholics. Table 2 shows that $97.0 \%$ alcoholics started drinking early, with special attention to two of them who started at seven years of age, obtaining an average age at the start of the addiction of 22 years and 24 years for increased consumption. Consumption has as primarily approximation factor $(66.7 \%)$ the influence of friends or family members, and $39.4 \%$ respondents said the father was the main responsible for their approximation to alcohol.

Table 2 - Characterization of levels of alcohol consumption and factors associated with the search for alcohol with the degree of kinship of the alcoholic

\begin{tabular}{lc}
\hline Variables & $\mathbf{f}(\%)$ \\
\hline Age at which consumption started (years) & $32(97.0)$ \\
$<20$ & $1(3.0)$ \\
$21-30$ & \\
Age at which consumption increased (years) & $20(60.6)$ \\
$<20$ & $6(18.2)$ \\
$21-30$ & $3(9.1)$ \\
$31-40$ & $2(6.1)$ \\
$41-60$ & $2(6.1)$ \\
Never & $22(66.7)$ \\
Factor that contributed to the approximation with alcohol \\
Influence of friends/family members & $9(27.3)$ \\
Personal and passionate problems & $4(12.1)$ \\
Curiosity & $2(6.1)$ \\
Depression & $1(3.0)$ \\
Soccer & \\
Close family members who abuse of alcohol & $13(39.4)$ \\
Father & $6(18.2)$ \\
Mother & $1(3.0)$ \\
Brother & $4(12.1)$ \\
Uncle & $3(9.1)$ \\
Grandparents & $6(18.2)$ \\
None &
\end{tabular}

The characterization of mothers of alcohol users and the information regarding the use of alcohol during lactation are shown in Table 3.
Results showed that $81.8 \%$ of mothers had their first pregnancy at the age of 16-20 years. Regarding the period of gestation, $87.8 \%$ of infants were born at term, that is, with a gestational age of 38 weeks. In regard to alcohol consumption, $75.8 \%$ did not drink alcohol before pregnancy, during the process of pregnancy, about $15.1 \%$ of women started or continued alcohol consumption, but $60.6 \%$ started or continued regularly using until the sixth month of lactation. The father was identified as the main family member abusing of alcohol in $45.4 \%$ of the women.

Table 3 - Characterization of mothers of alcoholics regarding the factors associated with alcohol intake and the degree of relatedness

\begin{tabular}{lc}
\hline Variables & $\mathbf{f}(\mathbf{\%})$ \\
\hline Gestation (weeks) & $3(9.1)$ \\
37 & $29(87.9)$ \\
38 & $1(3.0)$ \\
She doesn't remember & \\
Alcohol intake before pregnancy & $8(24.2)$ \\
Yes & $25(75.8)$ \\
No & \\
Alcohol intake during pregnancy & $5(15.2)$ \\
Yes & $28(84.8)$ \\
No & \\
Alcohol intake during lactation (months) & $5(15.2)$ \\
$<3$ & $20(60.6)$ \\
$3-6$ & $8(24.2)$ \\
Never & \\
Close family members who abuse of alcohol & $15(45.5)$ \\
Father & $6(18.2)$ \\
Mother & $5(15.1)$ \\
Uncle & $7(21.2)$ \\
None & \\
\hline
\end{tabular}

After application of the CAGE and T-ACE questionnaires, a survey of scores was conducted according to the individual score of the alcoholicsand their mothers was held valuation, and the Fisher test was carried out in order to verify the association of alcohol abuse of children in adulthood with alcohol consumption by the mother during the lactation. 
It was observed that 27 children who answered the CAGE questionnaire pointed out two or more positive responses, and that is why they were classified as alcoholics under outpatient treatment, while among their mothers, 20 of them drank alcohol during lactation and also pointed two positive responses, and were also classified as alcoholics.

According to the Fisher test, the value obtained in the correlation is low (0.036), indicating that there is no positive correlation between the factors tested, although it can be noted that the number of mothers who used alcohol during the breastfeeding process was high.

\section{Discussion}

The study had limitations related to the size of the sample, as many mothers of alcoholics who agreed to participate were no longer alive or had not performed the lactation process.

Research in human beings targeted to the understanding of the effects of alcohol consumption during lactation on infant development are scarce so far, and no research has been performed in order to correlate the onset of alcohol addiction to with alcohol consumption during lactation. In the present study, we sought to investigate the possible origin of alcohol abuse especially focusing on the influence of maternal behavior during lactation. Although few mothers of the alcoholics investigated here consumed alcohol during the pregnancy of their children, many of them did so during the lactation period. However, it was not possible to demonstrate a positive correlation between the consumption of alcohol by the mother and the addiction of children. The influence of others seems to be more important for the onset of addiction.

The profile of the alcoholics is consistent with the survey conducted in the last year by the World Health Organization, in which the male sex is predominant among drinkers worldwide ${ }^{(1)}$. Early contact with alcohol before the end of high school has been identified as an important factor for the onset of addiction in adolescents, and the lack of psychological support provided by the partner in individuals without stable relationship ${ }^{(9)}$.

The proximity to suppliers and contact with other addicts seem to favor the onset of the abuse in individuals of financially less favored social classes, high degree of vulnerability to social interactions and favorable conditions to bear the costs ${ }^{(10)}$. Interestingly, we found a very heterogeneous population as to education and financial conditions in which many addicts have some degree of education and family income of up to five minimum wages, suggesting that at least in this particular population, these factors were not decisive for beginning the addiction.

However, it was also observed that the start of alcohol consumption is strongly influenced by social interaction. Most patients reported that the proximity to alcohol was due to the influence of friends and family and $45.0 \%$ of mothers indicated the father figure. In fact, there is evidence that the more contact with people who make regular consumption of alcohol enhances the willingness to drink alcohol ${ }^{(2)}$. It is believed that when consumption happens within the home by the paternal or maternal figures, the consumption among children sounds like something natural for the family ${ }^{(11)}$. The close relationship between the consumption of alcohol by the mother and preterm birth requires the intake of two or more doses of alcohol per month, or in extreme cases of prematurity, about $36 \mathrm{~g} /$ day, corresponding to more than three daily doses of alcohol ${ }^{(12)}$. However, intake of more than four daily doses, or about more than $0.08 \mathrm{~g}$ would be associated with negative effects on the function of the child's motor development ${ }^{(13)}$. In fact, during the first trimester, the risk of oral clefts and fetal death increases with consumption of only 2 to 3.5 weekly doses of alcohol(14).

Studies in animals show that the use of a single dose of alcohol (classified as low consumption) has been observed to cause death of neuronal cells and microcephaly, that is, causing damage to the fetal nervous system ${ }^{(14)}$. It was found that only $24.0 \%$ of 
mothers said they had drank alcohol during pregnancy. This information associated with the low frequency of prematurity suggests that this factor probably did not influence the behavior of the alcoholics in this population. Alcohol intake during the breastfeeding process would affect three generations: the mother, the fetus and the offspring of the fetus, as it would raise the additional risks of alcohol abuse in the family, multiple morbidities and mental disorders ${ }^{(2)}$.

A study conducted in Australia with 6,597 women found that those who consume high levels of alcohol before pregnancy and reduced consumption after detecting that they were pregnant tended to increase consumption shortly after birth ${ }^{(15)}$. This behavior may also have occurred in the population investigated in this study, since most of them did not use alcohol during pregnancy and more than half reported they had consumed alcohol during lactation. Even not detecting a positive correlation between the mothers' alcohol consumption and addiction in children, our results highlight the high frequency of alcohol consumption by women during the lactation process.

It has been recently demonstrated that chronic exposure to ethanol in rats during both pregnancy and lactation may cause damages in brain development of the offspring in regions responsible for learning and memory due to a direct effect on alcohol on the metabolism of neurons ${ }^{(16)}$. This indicates a negative effect of alcohol intake during lactation over the development of the baby, whether indirectly by reducing the milk fraction ejected or directly by the transfer of alcohol metabolites in the breast milk for the infant.

Although we found a positive correlation between the consumption of alcohol by the mother and alcohol dependence in the adult child, we believe that the possible effects caused by alcohol on the development of the brain in infants, associated with favorable environmental, psychological and biogenetic conditions may increase the predisposition of an individual to become alcoholic. However, future studies need to be carried out to confirm our hypothesis. In every case, the data open space for reflections on the improvement of strategies for alcohol control, particularly for young people who are more prone to start the addiction and women during the breastfeeding period.

\section{Conclusion}

The alcoholic respondents were characterized by being predominantly males, single and by having started to consume alcohol before the age of twenty years. It was found that alcohol consumption by these individuals was worsened by living with other alcoholics or by the influence of friends and family members, especially the father. Alcohol consumption by mothers during pregnancy was not often observed in the survey, but they reported having consumed alcohol during the lactation period. Despite this fact, the existence of a correlation between the consumption of alcohol and addiction in children was not found.

\section{Collaborations}

Pacheco VA and Maximiano AP contributed to the project design and data collection. Sanches PBC and Bernuci MP contributed to the design, article writing, critical review of relevant content and approval of the final version to be published.

\section{References}

1. World Health Organization. Global status report on alcohol and health. Geneva: WHO; 2014.

2. Popova S, Lange S, Rehm J. Twenty percent of breastfeeding women in Canada consume alcohol. J Obstet Gynaecol. 2013; 35(8):695-6.

3. Rossi JAP, Santiago KB, Martins OA. Estudo da síndrome alcoólica fetal. Rev Eletr Edu Ciênc [Internet]. 2012 [cited 2015 set. 15]; 2(1):1-9. Available from: http://fira.edu.br/revista/reec vol2_num1_pag1.pdf 
4. Alencar-Júnior H, Ferraz RRN, Rodrigues FSM, Errante PR, Zanato LE, Silva RN. Conhecimento de alunos ingressantes de cursos da área da saúde sobre a síndrome alcoólica fetal. Rev UNILUS Ens Pesq. 2015; 12(27):32-5.

5. Santos NS, Souza EFM, Aquino AP, Santos JN, Bissaco DM, Suano ER, et al. A orientação de enfermagem a gestantes que fazem uso de álcool e tabaco. Rev Recient Enferm. 2014; 4(10):5-11.

6. Skogen JC, Overland S, Knudsen AK, Mykletun A. Concurrent validity of the CAGE questionnaire. The Nord-Trondelag Health Study. Addict Behav. 2011; 36(4):302-7.

7. Fabbri CE, Furtado EF, Laprega MR. Alcohol consumption in pregnancy: performance of the Brazilian version of the questionnaire T-ACE. Rev Saúde Pública. 2007; 41(6):979-84

8. Wenberg SL, Abramowitz SK. Statistics Using SPSS: An integrative approach. Cambridge University Press; 2008.

9. Reis TG, Oliveira LCM. Pattern of alcohol consumption and associated factors among adolescents students of public schools in an inner city in Brazil. Rev Bras Epidemiol. 2015; 18(1):1324.

10. Rozin L, Zagonel IPS. Risk factors for alcohol dependence in adolescents. Acta Paul Enferm. 2012; 25(2):314-8.
11. Willhelm AR, Cabral JCC, Steiger JO, Silva JFF, Ugarte LM, Almeida RMM. Consumo de álcool na adolescência e relação com uso excessivo de bebidas alcoólicas dos pais: estudantes de quatro escolas de Porto Alegre. Psico. 2015; 46(2):208-16.

12. Hackbarth BB, Ferreira JÁ, Carstens HP, Amaral AR, Silva MR, Silva JC. Suscetibilidade à prematuridade: investigação de fatores comportamentais, genéticos, médicos e sociodemográficos. Rev Bras Ginecol Obstet. 2015; 37(8):353-8.

13. Meyer-Leu Y, Lemola S, Daeppen JB, Deriaz O, Gerber S. Association of moderate alcohol use and binge drinking during pregnancy with neonatal health. Alcohol Clin Exp Res. 2011; 35(9):166977.

14. Alvik A, Aalen 00, Lindemann R. Early fetal binge alcohol exposure predicts high behavioral symptom scores in 5.5-year-old children. Alcohol Clin Exp Res. 2013; 37(11):1954-62.

15. Tran NT, Najman JM, Hayatbakhsh R. Predictors of maternal drinking trajectories before and after pregnancy: evidence from a longitudinal study. Aust N Z J Obstet Gynaecol. 2015; 55(2):123-30.

16. Cesconetto PA, Andrade CM, Cattani D, Domingues JT, Parisotto EB, Filho DW. Maternal exposure to ethanol during pregnancy and lactation affects glutamatergic system and induces oxidative stress in offspring hippocampus. Alcohol Clin Exp Res. 2016; $40(1): 52-61$. 